A.S. Kishkar, V.V. Kuryliuk

\title{
Molecular Dynamics Modeling of Thermal Conductivity of Silicon/Germanium Nanowires
}

\author{
Department of Physics, Taras Shevchenko National University of Kyiv, Kyiv 01601, 64/13, Volodymyrs'ka Str., \\ e-mail: kuryluk@univ.kiev.ua
}

\begin{abstract}
The thermal conductivity of silicon/germanium nanowires with different geometry and composition has been studied by using the nonequilibrium molecular dynamics method. The thermal conductivity of the $\mathrm{Si}_{1-x} \mathrm{Ge}_{x}$ nanowires is shown to firstly decrease, reaches a minimum at $x=0.4$ and then to increase, as the germanium content $x$ grows. It was found that in the tubular Si nanowires the thermal conductivity decreases monotonously with increasing radius of the cylindrical void. The phonon spectra were calculated and the mechanisms of phonon scattering in the investigated nanowires were analyzed.
\end{abstract}

Keywords: thermal conductivity, nanowire, silicon, germanium, molecular dynamics.

Article acted received 11.06.2018; accepted for publication 15.09.2018.

\section{Introduction}

Semiconducting silicon nanowires have attracted a great attention in recent years because of their excellent electrical and mechanical properties and the potential applications in many areas including solar cells [1], field effect transistors [2], lithium-ion batteries [3]. It is predicted that $\mathrm{Si}$ nanowires may soon become an efficient thermoelectric material $[4,5]$ since now it is possible to synthesize nanowires with controlled size, growth direction, and surface properties, as well as to build homogeneous wafer-scale arrays [6].

The efficiency of a thermoelectric material is characterized by the dimensionless figure of merit $Z T$, given by [7]

$$
Z T=S^{2} T \frac{\sigma}{k},
$$

where $S$ is the Seebeck coefficient, $\sigma$ the electrical conductivity, $T$ the temperature, and $k$ is the thermal conductivity. Therefore, lowering thermal conductivity without reducing electrical conductivity is desirable to improve the efficiency of thermoelectric energy conversion. According to current experiment [4-8], the Si nanowires with $Z T \sim 1$ has been achieved, it is about a 100-fold improvement over that of bulk silicon. Therefore, Si nanowires can usually be used to enhance the thermoelectric properties of other materials by lowering thermal conductivity.

Thermal conductivity of $\mathrm{Si}$ nanowires can be affected by many factors such as their lateral dimension and length, defects, strain, temperature etc. So far, many approaches have been proposed to further reduce thermal conductivity of nanowires for optimizing thermoelectric performance, such as the introduction of impurity scattering, holey structure, and surface roughness [9-11]. The recent advances in nanofabrication techniques make it possible to control the geometry of nanowires. Consequently, various nanostructuring pathways are proposed to construct diverse nanowires, such as superlattice nanowires [12] core-shell nanowires [13] porous nanowires [14] and kinked structure [15]. Another possible way to achieve this is a compound [16]. In this case, $\mathrm{Si}_{1-x} \mathrm{Ge}_{x}$ nanowires seems to be a promising candidate because both $\mathrm{Si}$ and Ge belong to the same group in the periodic table, have the same crystal structure, and display total solubility. Experimentally determination of the thermal properties of nanowires is difficult and sometimes impossible. Molecular dynamics (MD) simulation has been widely used to study the thermal properties of nanowires, as an alternative robust and reliable method.

In this paper, we explore how the combination of $\mathrm{Ge}$ content and geometry modification may be used to reduce the conductivity of $\mathrm{Si} / \mathrm{Ge}$ nanowires at room temperature. The dependence of the thermal conductivity of $\mathrm{Si}_{1-x} \mathrm{Ge}_{x}$ nanowires on the $x \mathrm{Ge}$ content and radius of cylindrical hole in $\mathrm{Si}_{1-x} \mathrm{Ge}_{x}$ nanowires was investigated using the nonequilibrium molecular dynamics method. 


\section{Research Methods}

In our simulations, nonequilibrium molecular dynamics method is adapted to calculate the thermal conductivity $k$. We employ the Tersoff potential to represent interactions between $\mathrm{Si}-\mathrm{Si}, \mathrm{Si}-\mathrm{Ge}, \mathrm{Ge}-\mathrm{Ge}$ atoms. Our model system consists of a single-crystalline $\mathrm{SiGe}$ nanowire with square cross-section, and tubular Si nanowire with cylindrical void (Fig.1). We have chosen the z-axis along the NW length, and we employ periodic boundary conditions in this direction. The initial $\mathrm{Si}$ nanowire is constructed from diamond-structured bulk silicon with 12 unit cells in the diameter $D_{N W}$, and 100 unit cells in the longitudinal direction which corresponds to a cross section area of $33.3 \mathrm{~nm}^{2}$ and a length of $L=54.3 \mathrm{~nm}$. The Si/Ge nanowire has been created by random substitution of $\mathrm{Ge}$ atoms with $\mathrm{Si}$. In order to create tubular $\mathrm{SiGe}$ nanowire, the $\mathrm{Si}(\mathrm{Ge})$ atoms are removed from the center of the nanowire forming a cylindrical cavity with radius $R_{h}$.

Before performing the nonequilibrium MD simulations for the thermal conductivity calculations, we thermalize and relax the initial structure of each system at zero pressure and target constant temperature using $N P T$-ensemble (constant particles number $N$, pressure $P$ and temperature $T$ ) to obtain their zero stress equilibrium state. Therefore, each nanowire structure was ensured to start the nonequilibrium MD simulations without any strain. In all MD simulations the equations of motion are integrated with a time step of 0.5 fs. All structures are thermally equilibrated for $250 \mathrm{ps}$, and then equilibrium simulations are carried out $1.5 \mathrm{~ns}$ to collect heat current data every time step for thermal conductivity analysis. Following equilibration, we computed the thermal conductivity of the system with nonequilibrium MD. More technical details about nonequilibrium molecular dynamics simulations can be found in Ref [17].

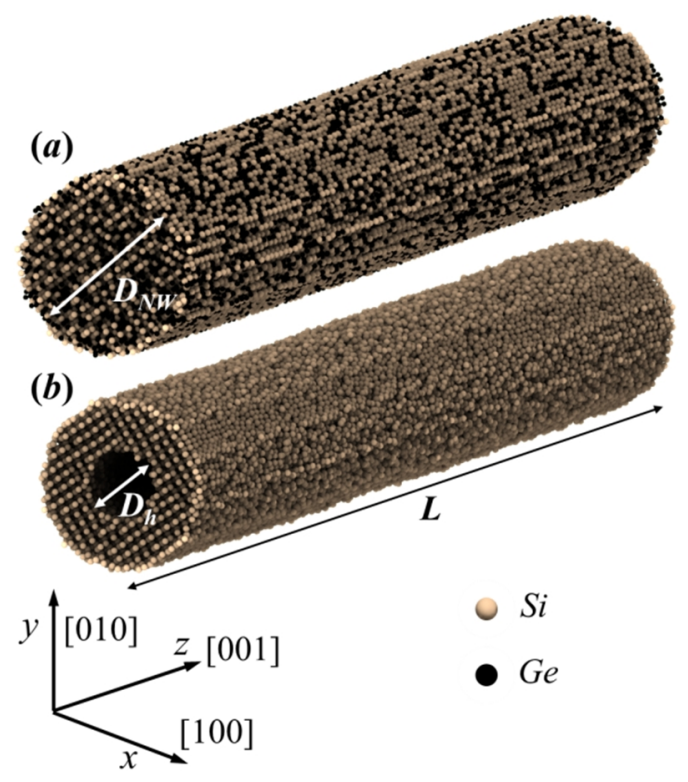

Fig. 1. Schematic illustration of $\mathrm{Si}_{1-x} \mathrm{Ge}_{x}$ nanowire (a) and Si tubular nanowire $(b)$

\section{Results and discussion}

First, we study the effect of Ge content $\mathrm{x}$ on the thermal conductivity of $\mathrm{Si}_{1-x} \mathrm{Ge}_{x}$ nanowires. The results of the thermal conductivity calculations at $300 \mathrm{~K}$ are shown in Fig. 2, where the value of $k$ is plotted as a function of atomic percent germanium. It is found that increasing the $\mathrm{Ge}$ concentration leads to a very fast decrease of thermal conductivity when $x<0.1$. Keep increasing $x$, the curve of $k$ then tends to saturate at a minimum value $k_{\min }=1.6 \mathrm{~W} / \mathrm{m} \cdot \mathrm{K}$ around $x=0.4$. Crossing through this minimum point, the thermal conductivities increase progressively with the increasing $\mathrm{Ge}$ concentration. This concentration dependence of nanowires is very similar to the experimentally-observed one of bulk $\mathrm{Si}_{1-x} \mathrm{Ge}_{x}$ alloy. These changes are attributed to a decrease in the phonon mean free path due to the scattering by the solution strain associated with the alloying component.

Another important application of the present study is to tailor thermal conductivity by geometry of $\mathrm{Si}$ nanowire. We now turn to the reduction of thermal conductivity by using tubular structure. To investigate the thermal conductivity of tubular nanowire, the cylindrical voids with various radiuses are generated by removal of silicon atoms from the perfect $\mathrm{Si}$ nanowire. As shown in Fig. 3, the results of MD simulation show that the thermal conductivity of tubular $\mathrm{Si}$ nanowires decreases with the radius of cylindrical void's increase. A very small hole with radius only $10 \%$ of the nanowire radius induces a fivefold reduction in room temperature thermal conductivity. Moreover, with the radius of the cylindrical void about $75 \%$ of the nanowire radius, thermal conductivity of Si nanowire is only about $10 \%$ of that of Si nanowire at room temperature.

Changes in thermal conductivity, caused by the variation of Ge content or the nanowires' geometry, were analyzed with the nanostructures' phonon spectra (Fig. 4). The calculation of the phonon spectra was made employing the Fourier transform of velocity autocorrelation function [18]. In the solid Si nanowire, there are conspicuous spectral bands that represent

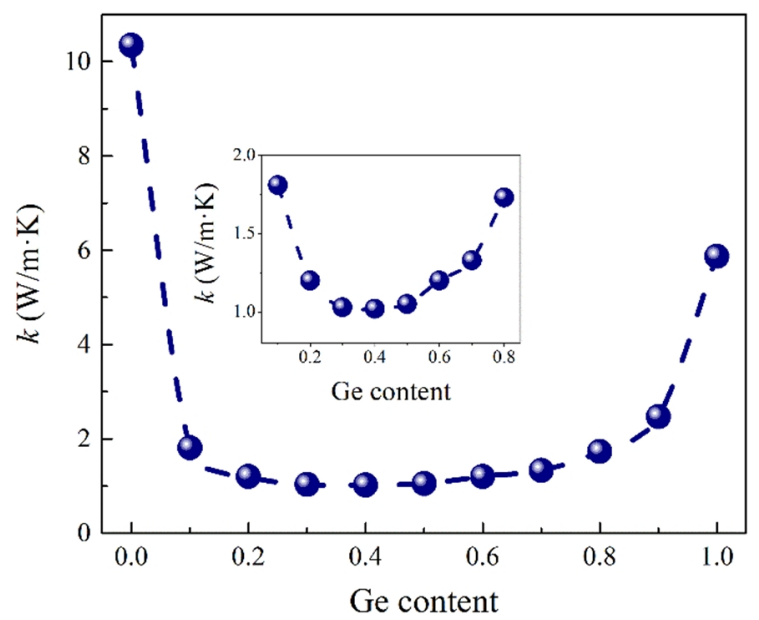

Fig. 2. Thermal conductivity of $\mathrm{Si}_{1-x} \mathrm{Ge}_{x}$ nanowire versus Ge content $x$ at $300 \mathrm{~K}$. In insertion - the part of $k(x)$ curve at $0.1<\mathrm{x}<0.8$ 


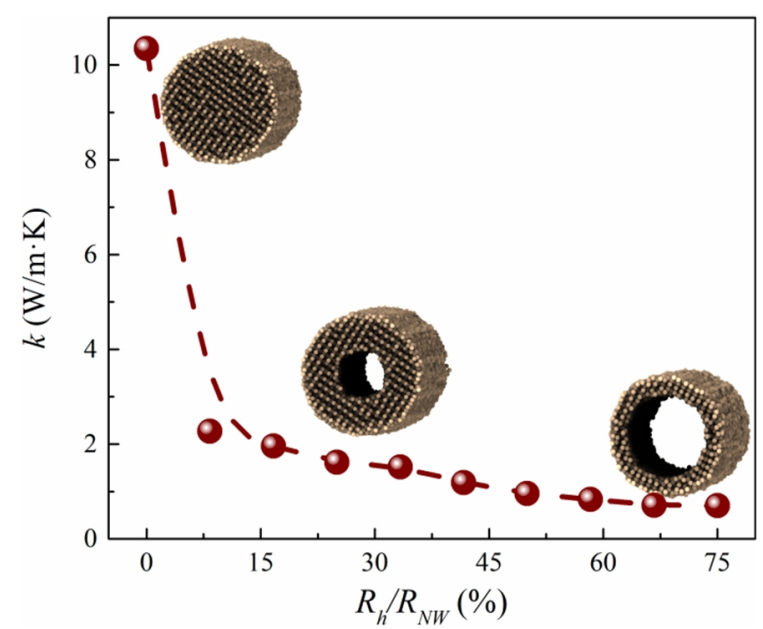

Fig. 3. Thermal conductivity of tubular Si nanowire versus the radius of cylindrical void at $300 \mathrm{~K}$.

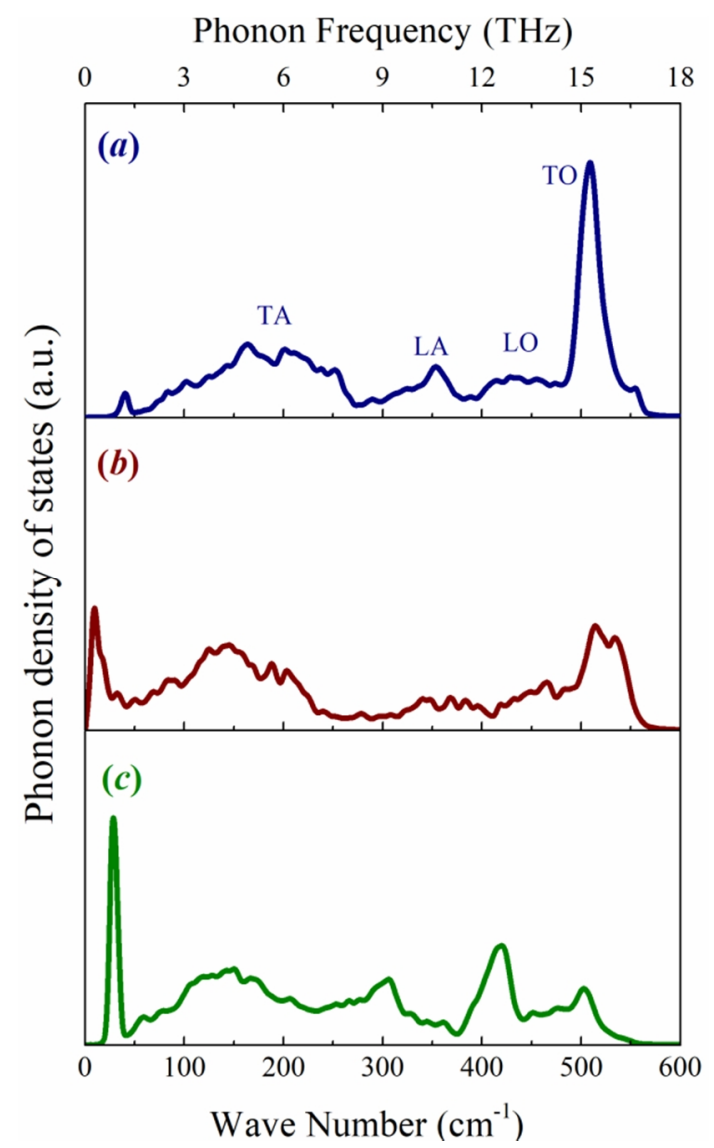

Fig. 4. Phonon spectra of a solid $\mathrm{Si}$ nanowire (a), tubular $\mathrm{Si}$ nanowire $(b)$, and solid $\mathrm{Si}_{0.5} \mathrm{Ge}_{0.5}$ nanowire (c). The bands of the phonon spectra: TA and LA transverse and longitudinal acoustic, TO i LO transverse and longitudinal optical optical and acoustical phonon modes (Fig. 4, a), while the overall spectrum is close to that of the bulk $\mathrm{Si}$. When the nanowire has a cylindrical void, the considerate decrease of high-frequency modes (Fig. 4, b), which refer to optical vibrations, is observed. Meanwhile, tubular nanowire's spectrum has a low-frequency intensity band, which is hardly observed in the spectrum of a solid $\mathrm{Si}$ nanowire. Similar transformations of phonon spectrum take place in $\mathrm{Si}_{0.5} \mathrm{Ge}_{0.5}$ solid nanowire (Fig. 4, c). Partial substitution of $\mathrm{Si}$ with $\mathrm{Ge}$ atoms also reduces phonon LO and TO bands and leads to low-frequency peak, which is most probably refers to TA phonons.

Revealed changes in thermal conductivity and in phonon spectra in the researched nanowires are related, as we believe, to the formation of the additional scattering centers. In the case of tubular nanowire, these centers are the inner surface of the structure, whereas in $\mathrm{Si}_{1-x} \mathrm{Ge}_{x}$, they are heterogeneity of the nanowire's components, i.e. the chaotic Ge atom's placement in the $\mathrm{Si}$ lattice. Since the void's radius and the average distance between Ge atoms are about 0.1-1 nm, the highfrequency phonons experience scattering the most, having a short mean free path. As a result, highfrequency modes' contribution into thermal conduction decreases which leads to the general decrease of thermal conductivity. It is worth mentioning that the increase of low-frequency phonon bands' intensity in the Si tubular and the SiGe solid nanowires with the simultaneous decrease of their thermal conductivity indicates that the aforementioned bands are localized. Similar localized phonon modes were discovered in $\mathrm{Si} / \mathrm{Ge}$ core-shell nanowires [19].

\section{Conclusion}

1. Molecular dynamics modeling of thermal conductivity in SiGe nanowires of different content and geometry was conducted in this paper.

2. It is demonstrated that through the Ge content variation and a cylindrical void in $\mathrm{Si}$ nanowires approximately 10 -fold reduction of thermal conductivity is observed.

3. The results of the thermal conductivity modeling are analyzed with a reference to the phonon spectra transformation of the nanowires in the research.

4. The results in the paper can be used for designing thermoelectric elements, based on SiGe nanowires.

Kishkar A. - Student, department of metal physics; Kuryliuk $\boldsymbol{V}$. - PhD of physics and mathematics, associate professor, department of metal physics.

[1]. P. Yu, J. Wu, S. Liu, J. Xiong, C. Jagadish, Z. M.Wang, Nano Today, 11(6), 704 (2016).

[2]. B. Wang, T. Stelzner, R. Dirawi, O. Assad, N. Shehada, S. Christiansen, and H. Haick, ACS Appl. Mater. Interfaces, 4(8), 4251 (2012).

[3]. M. Zamfir, H. Nguyen, E. Moyen, Y. Lee, and D.Pribat, J. Mater. Chem. A, 1, 9566 (2013).

[4]. A. Boukai, Y. Bunimovich, J. Tahir-Kheli, J. Yu, W.Goddard, J. Heath, Nature, 451, 168 (2008).

[5]. G. Schierning, Phys. Status Solidi A, 211(6), 1 (2014).

[6]. G. Gadea, A. Morata, A. Tarancon, Semiconductors and Semimetals, 2018 (In press).

[7]. A. Majumdar, Science, 303, 777 (2004). 
[8]. A. Hochbaum, R. Chen, R. Delgado, W. Liang, E. Garnett, M. Najarian, A. Majumdar and P. Yang, Nature, 451, 163 (2008).

[9]. Y. Wang, B. Liab and G. Xie, RSC Adv., 3, 26074 (2013).

[10]. J. Lee; J. Lim; P. Yang, Nano Lett., 15, 3273 (2015).

[11]. J. Lim, K. Hippalgaonkar, S. Andrews, A. Majumdar, and P. Yang. Nano Lett., 12, 2475 (2012).

[12]. M. Hu and D. Poulikakos, Nano Lett. 12, 5487 (2012).

[13]. G. Xie, B. Li, L. Yang, J. Cao, Z. Guo, J. Appl. Phys., 113, 083501 (2013).

[14]. Y. Zhao, L. Yang, L. Kong, M. Nai, D. Liu, J. Wu, Y. Liu, S. Chiam, W. Chim, C. Lim, B. Li, J. Thong, and K. Hippalgaonkar, Adv. Funct. Mater., 27, 1702824 (2017).

[15]. J. Jiang, N. Yang, B. Wang, and T. Rabczuk, Nano Lett., 13, 1670 (2013).

[16]. H. Kim, I. Kim, H. Choi, and W. Kim, Appl. Phys. Lett. 96, 233106 (2010).

[17]. V.Kuryliuk, O. Korotchenkov, Physica E: Low-dimensional Systems and Nanostructures, 88, 228 (2017).

[18]. D. Noid, M. Koszykowski, and R. Marcus, The Journal of Chemical Physics, 67, 404 (1977).

[19]. M. Hu, K. Giapis, J. Goicochea, X. Zhang, and D. Poulikakos, Nano Lett., 11, 618 (2011).

\author{
А.С. Кішкар, В.В. Курилюк
}

\title{
Молекулярно-динамічне моделювання коефіціснта теплопровідності кремній/германісвих нанониток
}

\author{
Київський наиіональний університет імені Тараса Шевченка, 01601, м. Київ, вул. Володимирська 64/13, \\ e-mail: kuryluk@univ.kiev.ua
}

\begin{abstract}
3 використанням методу нерівноважної молекулярної динаміки розраховано коефіцієнт теплопровідності кремній/германієвих нанониток різної геометрії і компонентного складу. Показано, що при зростанні вмісту германію $x$, теплопровідність нанониток $\mathrm{Si}_{1-x} \mathrm{Ge}_{x}$ зменшується, досягає мінімуму при $x=0,4$ i поступово починає зростати. Виявлено, що в порожнистих $\mathrm{Si}$ нанонитках коефіцієнт теплопровідності монотонно зменшується при зростанні радіуса порожнини. Розраховано фононні спектри та проаналізовано механізми фононного розсіювання в досліджуваних нанонитках.

Ключові слова: коефіцієнт теплопровідності, нанонитка, кремній, германій, молекулярна динаміка.
\end{abstract}

